\title{
Induced Variation in Tetraploid Rudbeckia subtomentosa 'Henry Eilers' Regenerated from Gamma-irradiated Callus
}

\author{
Kelly M. Oates ${ }^{1}$, Darren H. Touchell ${ }^{2,4}$, and Thomas G. Ranney ${ }^{3}$ \\ Mountain Crop Improvement Laboratory, Department of Horticultural \\ Science, Mountain Horticultural Crops Research and Extension Center, \\ North Carolina State University, 455 Research Drive, Mills River, NC \\ 28759-3423
}

Additional index words. Asteraceae, autotetraploid, black-eyed Susan, coneflower, induced mutation, plant breeding

\begin{abstract}
Rudbeckia subtomentosa 'Henry Eilers' is an adaptable and popular garden plant; however, reduction in height and increased novelty in flower color would be desirable. The effect of gamma radiation dose on in vitro survival and development, and ex vitro fertility, phenology, and morphology of tetraploid Rudbeckia subtomentosa 'Henry Eilers' was investigated. In vitro embryogenic callus was treated with gamma radiation $(0,5,10,20$, or $40 \mathrm{~Gy})$. Rooted microshoots were established ex vitro and evaluated for morphology (plant height, number of flowers, diameter of the terminal flowers, diameter of the secondary flowers, number of stems, number of nodes, and internode length), date of first anthesis, winter survival, and pollen fertility on mature, second-year plants. Callus survival had no response to dose 2 months after treatment; however, microshoot number was significantly reduced with increasing dose. In vitro microshoot survival continued to decline at higher doses up to 4 months after treatment. Plant height, average stem height, number of flowers, flower diameter, percent winter survival, and pollen viability were all reduced with increasing radiation dose. Date of first anthesis was also delayed with increased radiation dose. Several off phenotypes were recorded including increased apical splitting of the ray florets in several plants. Gamma radiation was somewhat effective for reducing the height of $R$. subtomentosa 'Henry Eilers,' but flower morphology, flower number, and plant overwintering survival were often negatively affected with increasing radiation dose. Treating callus with low levels of gamma radiation $(5-10 \mathrm{~Gy})$ resulted in relatively high in vitro and field survival while inducing a range of other mutations that could be selected.
\end{abstract}

The genus Rudbeckia (black-eyed Susan or coneflower) consists of $\approx 30$ species, all of which are native to North America (Armitage, 1997; Palmer et al., 2009). The genus includes annual, biennial, and perennial species (Perdue, 1957). Rudbeckia is a durable and popular perennial with broad adaptability

Received for publication 25 Feb. 2013. Accepted for publication 15 May 2013.

This research was funded in part by the North Carolina Agricultural Research Service (NCARS), Raleigh, NC.

Technical assistance of Joel Mowrey, Nathan Lynch, Tom Eaker, and Jeremy Smith and the staff at the Mountain Horticultural Crops Research Station is gratefully appreciated.

Use of trade names in this publication does not imply endorsement by the NCARS of products named nor criticism of similar ones not mentioned. This research is from a M.S. thesis by the senior author.

${ }^{1}$ Graduate Research Assistant.

${ }^{2}$ Research Scholar.

${ }^{3}$ Professor.

${ }^{4}$ To whom reprint requests should be addressed; e-mail darren_touchell@ncsu.edu.
(Armitage, 1997). The Perennial Plant Association named Rudbeckia fulgida var. sullivantii 'Goldsturm' perennial plant of the year in 1999. However, $R$. 'Goldsturm' is susceptible to downy mildew (Plasmopara halstedii) and leaf spot (Cercospora spp.) that can severely stunt and disfigure foliage and plants (Fulcher et al., 2003; Hong, 2006). Rudbeckia subtomentosa 'Henry Eilers' is an alternative coneflower species with excellent disease resistance and unique flower form with tubular ray florets. However, like with most $R$. subtomentosa, this cultivar tends to be too tall (greater than $1 \mathrm{~m}$ ) for many landscape uses. A reduction in height of these plants as well as increased novel traits in flower color or form would be desirable.

Induced mutations are commonly used in plant breeding to create genetic variability. Mutations can be induced by both physical and chemical agents (van Harten, 1998). Fast neutron and ionizing radiation are two methods of physically inducing mutations. Although fast neutrons have high relative biological effectiveness (i.e., greater biological effects with lower doses), use of neutrons as a radiation source requires more specialized equipment, either a nuclear reactor or particle accelerator, both of which can produce considerable heat and can cause residual radioactivity in the plant material. Alternatively, the use of ionizing radiation (x-rays or gamma rays) does not result in any residual radioactivity in the plant material (van Harten, 1998). Gamma radiation can be provided by a ${ }^{60} \mathrm{Co}$ source, which is more commonly available, inexpensive to operate, and produces minimal heat at low activity. Gamma radiation was first discovered in 1900 by P. Villard and has been identified since the 1950 s as a radiation source for inducing mutations in plant material (Sparrow, 1954; van Harten, 1998).

Radiation can alter plants in several ways including changing plant architecture, growth rate, flower and foliage color and shape, fruit characteristics, chemical composition, and resistance to diseases and pests (Broertjes et al., 1988; Dao et al., 2006; van Harten, 1998). Radiation can affect plant height by reducing the number of nodes and the length of internodes (Gottschalk and Wolff, 1983). Radiation has been used as a tool to induce mutations for the development of commercial varieties in many crop species, particularly the forages as well as in ornamental crops such as Chyrsanthemum (Dao et al., 2006), Dendranthemum grandiflorum (Datta et al., 2001), Nelumbo nucifera (Arunyanart and Soontronyatara, 2002), Rosa hybrida (Arnold et al., 1998; Gupta and Shukla, 1971; van Harten, 1998), and Buddleia (Dai and Magnusson, 2012).

Rudbeckia 'Henry Eilers' is typically propagated asexually to maintain the desirable tubular ray floret trait. Mutation treatment of vegetative tissue such as buds or cuttings often results in chimeras (Datta et al., 2001) as a result of the complexity and number of initial/stem cells in the apical meristem and the potential for each cell to be affected differently. In vitro treatment of organogenic callus can result in fewer chimeric mutations because plants are being regenerated from one or a few individual cells. Gamma irradiation of callus tissue has been used to induce mutations in several crop species including Stenotaphrum secundatum [St. Augustinegrass (Li et al., 2010)], Capparis spinosa [Caper (Al-Safadi and Elias, 2011)], Vitis sp. [grape (Kuksova et al., 1997)], Saccharum sp. [sugarcane (Suprasanna et al., 2008)], and Persea americana [avocado (Witjaksono and Litz, 2004)].

To date, there have been no reports of the use of gamma irradiation to induce mutations in embryogenic callus of Rudbeckia spp. The objective of this study was to evaluate survival, morphology, fertility, and phenotypic variation of tetraploid $R$. 'Henry Eilers' regenerated from gamma-irradiated embryogenic callus to better understand effects and optimal dosages.

\section{Materials and Methods}

In vitro culture and gamma irradiation. Tetraploid $R$. 'Henry Eilers' plants were previously generated and maintained in vitro 
at the Mountain Crop Improvement Laboratory (Palmer et al., 2008). Leaves from in vitro-maintained microcuttings were used as explants. Embryogenic callus cultures of tetraploid $R$. 'Henri Eilers' were initiated in Oct. 2009 on Murashige and Skoog (MS) basal salts and vitamins (Murashige and Skoog, 1962) supplemented with $0.1 \mathrm{~g} \cdot \mathrm{L}^{-1}$ myoinositol, $0.1 \mathrm{~g} \cdot \mathrm{L}^{-1}$ 2-(N-Morpholino) ethanesulfonic acid (MES) monohydrate, $5 \mu \mathrm{M}$ 6-benzylaminopurine (BAP), $0.625 \mu \mathrm{M}$ 1-napthyl acetic acid, $30 \mathrm{~g} \cdot \mathrm{L}^{-1}$ sucrose, $\mathrm{pH}$ adjusted to $5.75 \pm 0.03$, and solidified with $7.5 \mathrm{~g} \cdot \mathrm{L}^{-1}$ agar. Callus tissue was plated onto fresh media 1 week before irradiation treatment (23 Nov. 2009). Levels of gamma radiation treatments included $0,5,10,20$, and 40 Gy with six plates per treatment and six callus units (subsamples, $\approx 0.5 \mathrm{~cm}^{2}$ ) per plate. Radiation treatments were applied by exposing cultures to ${ }^{60} \mathrm{Co}$ for sufficient durations to accumulate the desired total dose.

Cultures were irradiated on 30 Nov. 2009. Callus was kept in the dark at $23 \pm 2{ }^{\circ} \mathrm{C}$ before and after treatment. Callus was transferred to fresh media $19 \mathrm{~d}$ posttreatment (18 Dec. 2009), and callus survival and number of microshoots per callus were recorded. Microshoot number per callus and number of dead microshoots were again recorded $60 \mathrm{~d}$ posttreatment (29 Jan. 2010) to determine if radiation treatment influenced callus survival and regenerative capacity. A random sample of seven microshoots per original plate resulting in 42 microshoots per treatment was transferred onto a shoot regeneration media: Driver and Kuniyuki Walnut (DKW) basal salts and vitamins (Driver and Kuniyuki, 1984) supplemented with $0.1 \mathrm{~g} \cdot \mathrm{L}^{-1}$ myoinositol, $0.1 \mathrm{~g} \cdot \mathrm{L}^{-1} \mathrm{MES}$ monohydrate, $2 \mu \mathrm{M}$ BAP, $30 \mathrm{~g} \cdot \mathrm{L}^{-1}$ sucrose, solidified with $7.5 \mathrm{~g} \cdot \mathrm{L}^{-1}$ agar and $\mathrm{pH}$ adjusted to $5.75 \pm 0.03$, and maintained under standard culture conditions $\left[23 \pm 2{ }^{\circ} \mathrm{C}\right.$ and a 16 -h photoperiod of $75 \mu \mathrm{mol} \cdot \mathrm{m}^{-2} \cdot \mathrm{s}^{-1}(400-700 \mathrm{~nm})$ provided by cool-white fluorescent lamps] for three subculturing cycles $(\approx 12$ weeks). Survival of microshoots was recorded on 12 May 2010 and surviving microcuttings were placed onto a rooting media consisting of MS basal salts and vitamins supplemented with $0.1 \mathrm{~g} \cdot \mathrm{L}^{-1}$ myoinositol, $0.1 \mathrm{~g} \cdot \mathrm{L}^{-1} \mathrm{MES}$ monohydrate, $5 \mu \mathrm{M}$ indole3-butyric acid, $30 \mathrm{~g} \cdot \mathrm{L}^{-1}$ sucrose, $\mathrm{pH}$ adjusted to $5.75 \pm 0.03$, solidified with $7.5 \mathrm{~g} \cdot \mathrm{L}^{-1}$ agar, and maintained under standard culture conditions for 1 week. Rooted microshoots were then transferred ex vitro into 72-cell trays and maintained under mist in a completely randomized design. After 4 weeks, plants were transferred from 72 -cell trays to 0.80 -L pots in a $100 \%$ pine bark media [supplemented with $1.04 \mathrm{~kg}$ lime and $0.74 \mathrm{~kg}$ granular micronutrients (Micromax ${ }^{\circledR}$; The Scotts Co., Marysville, $\mathrm{OH})$, per cubic meter]. After an additional 12 weeks, plants were transferred to the field in a completely randomized design with $\approx 40$ per treatment and overwintered for one season before data were collected. Shoot number and shoot survival were analyzed using regression analysis (PROC GLM, SAS Version 9.1.3; SAS Institute Inc., Cary, NC).
Evaluation of morphology, phenology, survival, and pollen viability. Plant height, number of flowers, diameter of flowers (six per plant), date of first anthesis, winter survival, pollen viability, number of stems, number of nodes, and internode length data were collected on mature second-year $\mathrm{M}_{1}$ plants, where the $M_{1}$ generation was the generation receiving the treatment. Data were collected daily to capture the first date of anthesis (date of first pollen shed), and data for all other traits were collected once all plants had reached anthesis (3 Aug. 2011 and 8 Aug. 2011). Data were analyzed using regression analysis (PROC GLM, SAS Version 9.1.3).

To evaluate male fertility, pollen was collected from newly opened florets from each plant between $1030 \mathrm{HR}$ and $1130 \mathrm{HR}$. Pollen was placed on a glass slide and stained with $40 \mu \mathrm{L}$ of acetocarmine $(1 \%)$, covered with a coverslip, and allowed to incubate for a minimum of $90 \mathrm{~min}$ at room temperature. Pollen was observed the same day collected. Well-formed grains with a pink/red stain were scored as viable. Each sample consisted of a minimum of 200 grains and was collected from a minimum of three flowers per plant. Data were analyzed using regression analysis (PROC GLM, SAS Version 9.1.3).

\section{Results and Discussion}

Callus survival and shoot regeneration. Callus survival and microshoot regeneration showed no significant response to radiation dosage 3 weeks after treatment (data not shown). Furthermore, callus survival was not significantly affected by radiation dose $60 \mathrm{~d}$ after treatment (29 Jan. 2010; data not shown). However, $60 \mathrm{~d}$ after treatment, microshoot regeneration from callus showed a significant, quadratic decline in response to radiation dose with shoot production decreasing to less than five microshoots per callus at dosages greater than 20 Gy $(P<$ 0.05 ) (Fig. 1A). Similarly, survival of regenerated microshoots after three subcultures (12 May 2010) showed a quadratic decrease in response to dose $(P<0.05)$ with survival decreasing to $0 \%$ at 40 Gy (Fig. 1B). Witjaksono and Litz (2004) also found radiation treatments influenced regenerative and developmental capacity of embryogenic callus of avocado (Persea americana). Although radiation dose did not affect the number of early-stage somatic embryos, higher dosages (10 Gy or greater) inhibited the maturation of somatic embryos (Witjaksono and Litz, 2004). Charbaji and Nabulsi (1999) found low doses of radiation can increase in vitro vigor in grapevine (Vitis vinifera). Although we did not evaluate in vitro growth responses in the current study, high survival of microshoots was maintained at low doses of radiation (Fig. 1B).

Morphology, date of anthesis, winter survival, and pollen viability. Radiation dose had a significant effect on plant height, number of flowers, winter survival, and pollen staining $(P<0.05)$ (Fig. 2). There was no dosage effect on the number of stems, number of nodes, or internode length (data not shown). Plant height, number of flowers, flower diameter, winter survival, and pollen
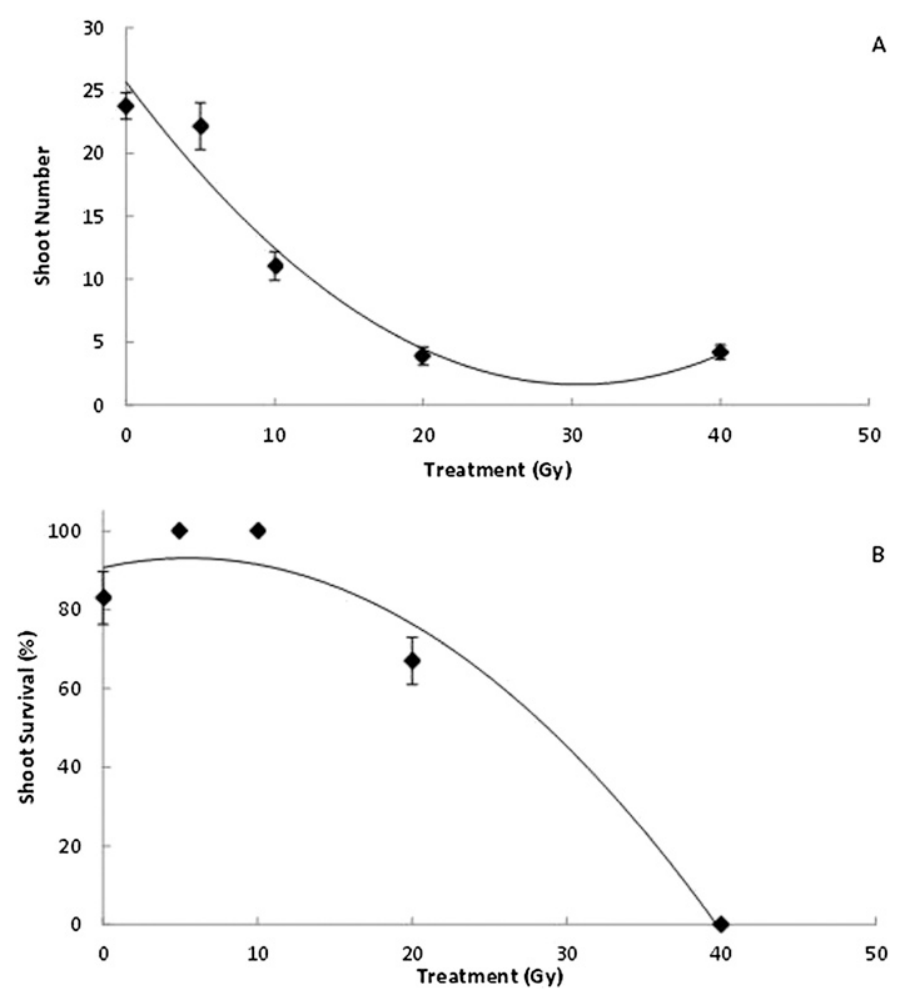

Fig. 1. In vitro shoot number and shoot survival of tetraploid $R$. 'Henry Eilers' treated with gamma radiation (means \pm SEM). (A) Number of shoots per callus (29 Jan. 2010); $\mathrm{y}=25.69-1.58 \mathrm{x}+0.03 \mathrm{x}^{2}(P<$ $\left.0.0007, r^{2}=0.94\right)$. (B) Shoot survival (12 May 2010) $\mathrm{y}=91.0+0.8 \mathrm{x}-0.08 \mathrm{x}^{2}\left(P<0.01, r^{2}=0.96\right)$. 


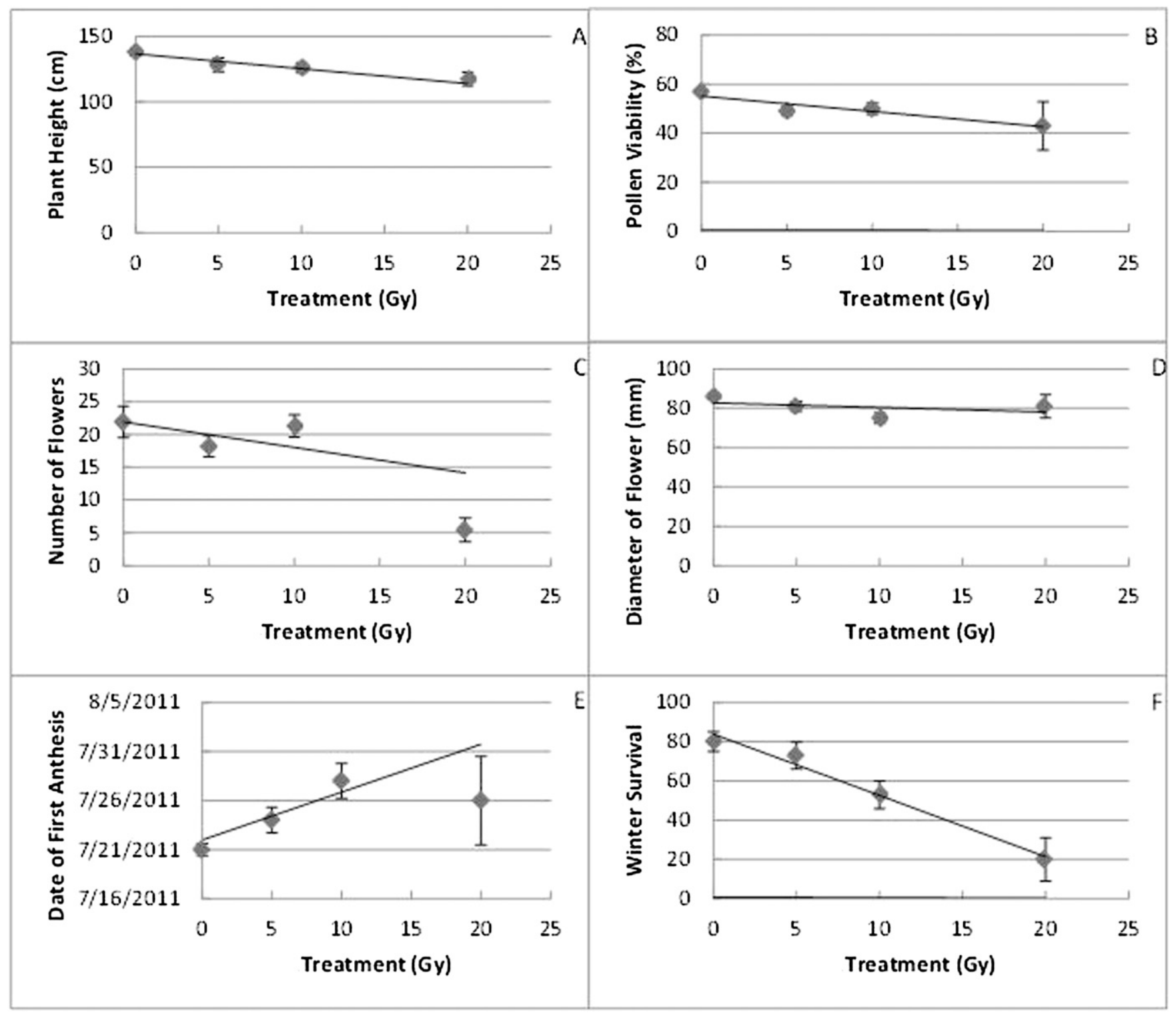

Fig. 2. Response of selected traits to radiation dose (means \pm SEM). Solid line represents linear regression. (A) Plant height, $\mathrm{y}=136.67-1.14 \mathrm{x}\left(P=0.01, r^{2}=0.98\right)$. (B) Pollen staining, $\mathrm{y}=55.2-0.0 .6 \mathrm{x}\left(P=0.001, r^{2}=0.85\right)$. (C) Number of flowers, $\mathrm{y}=21.92-0.39 \mathrm{x}\left(P=0.04, r^{2}=0.98\right)$. (D) Diameter of flower, $\mathrm{y}=82.8-$ $0.23 \mathrm{x}\left(P<0.05, r^{2}=0.2\right)$. (E) Date of first anthesis, $\mathrm{y}=40746+0.48 \mathrm{x}\left(P<0.05, r^{2}=0.98\right)$. (F) Winter survival, $\mathrm{y}=84-3.0 \mathrm{x}\left(P<0.0001, r^{2}=0.98\right)$.

viability all had a negative linear relationship with radiation dose (Fig. 2). The date (Julian day) of first anthesis had a positive linear response to dose. Interestingly, both internode length and number of nodes had a small negative response to dosage, explaining an overall significant reduction in height. The low $r^{2}$ value for all variables reflects the variability of our data. Similar to our study, variability in morphological traits in response to radiation dose has also been observed in gamma-irradiated shoot tips of Buddleia cultivars (Dai and Magnusson, 2012). Given the random nature of mutation treatments to DNA, this is not unexpected.

Overall, mutation treatments influenced the growth and development of tetraploid R. subtomentosa 'Henri Eilers'. Reduced plant height is a common response to radiation and numerous varieties of grains and crop species have been improved using mutation treatments [see van Harten (1998) for review]. Similar to our study, a decrease in the total number of flowers, flower size, and plant height in response to radiation dose has also been observed in gamma-irradiated cuttings of Chrysanthemum (Dilta et al., 2003). Furthermore, mutation treatments are often used to induce sterility. Although we had only a moderate decline in pollen staining in response to radiation dose, a considerable (greater than $71 \%$ ) reduction in pollen viability in response to gamma irradiation has been observed in citrus (Bermejo et al., 2011).

In our study, we observed both a reduced number of flowers and date of first anthesis. Although mutations toward late blooming are common, they are generally undesirable in many agronomic crops and are often selected against in $\mathrm{M}_{1}$ and $\mathrm{M}_{2}$ mutagenic populations (van Harten, 1998). In African marigold (Tagetes erecta), bud initiation, days to first color, and days to first bloom were all delayed with 200-, 300-, and 400-Gy treatments of seed (Singh et al., 2009). The number of flower heads per plant was also significantly reduced in African marigold with all radiation treatments (Singh et al., 2009).

Interestingly, there was a reduction in winter survival with higher radiation dose. Although reduction in winter survival is generally undesirable and has not been addressed in most mutation studies, increased cold tolerance has been reported. For example, mutants with higher cold tolerance have been selected from radiation treatments in vitro in rice (Oryza sativa) (Rakotoarisoa et al., 2008). X-ray radiation has been used to develop cold-tolerant chrysanthemum (Huitema et al., 1991).

We also observed unusual qualitative traits (Fig. 3) such as mutations in ray floret morphology in response to irradiation. Unusual 


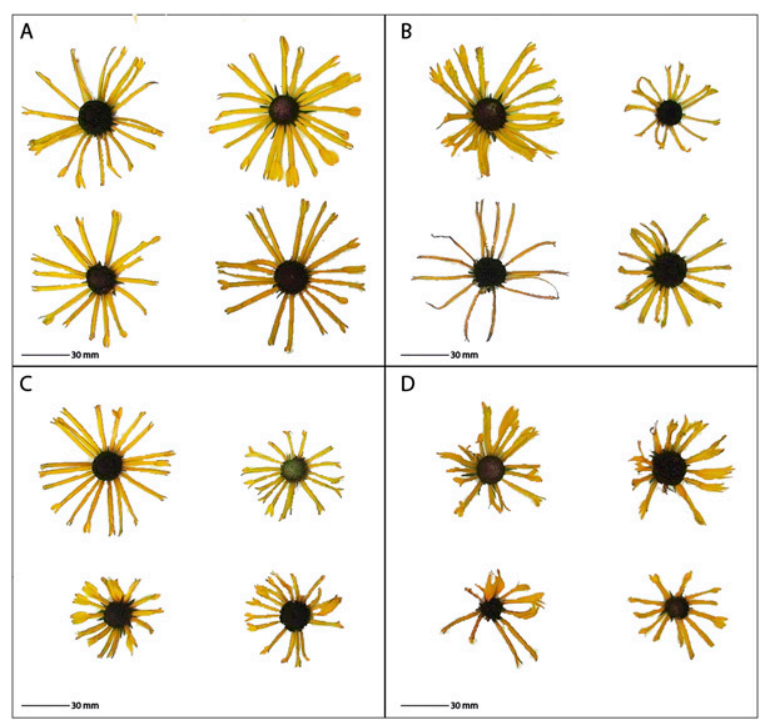

Fig. 3. Off phenotypes from treatments and control. (A) Normal phenotype. (B) Off types from 5-Gy treatment. (C) Off types from 10-Gy treatment. (D) Off types from 20-Gy treatment.

phenotypes in the 5-Gy treatment included ray florets with increased apical splitting, cupping of the ray florets, and a decrease in the diameter of the ray floret. The 10-Gy treatment displayed some increased apical splitting of the ray floret and one mutant with green disc florets as opposed to the black/ brown color of the control. The 20-Gy treatment showed more severe apical splitting of the ray floret than was found in the lower treatments and a more irregular presentation of ray florets around the disc head. Irregularity of the ray floret distribution around the disc has also been noted in gamma-irradiated Chyrsanthemum (Dao et al., 2006). Irregular ray floret morphology has also been noted in gamma-irradiated aster (Aster novi-belgii) cultivars (Kristiansen and Petersen, 2009) and African marigold (Singh et al., 2009). No change in flower color was observed in our study.

In some cases, mutations can result in dominant gene mutations that are apparent in $\mathrm{M}_{1}$ phenotypes; this has been observed in maize, barley, and other crop species (van Harten, 1998). However, the majority of gene mutations occurring in plants as a result of induced mutations are typically recessive or quantitative (Stadler, 1944; van Harten, 1998). As such, phenotypes associated with the mutation may not be observed until later generations. Because R. subtomentosa is highly self-infertile (Palmer et al., 2009), it is difficult to develop lines with homozygous, recessive mutations. However, crosses of plants with complimentary dominant mutations (e.g., reduced height) may further enhance those traits.

Treating callus with low levels of gamma radiation (5-10 Gy) resulted in relatively high in vitro and field survival while inducing a range of other mutations. Several accessions with a reduced height and a desirable flower form were selected from the 5- and $10-\mathrm{Gy}$ treatments for further assessment of commercial traits. Higher doses resulted in increased and undesirable irregularity of the ray floret morphology. Development of larger populations of plants derived from 5- to 10-Gy treatments would be a promising approach to recover combinations of desirable mutations.

\section{Literature Cited}

Al-Safadi, B. and R. Elias. 2011. Improvement of caper (Capparis spinosa L.) propagation using in vitro culture and gamma irradiation. Sci. Hort. 127:290-297.

Armitage, A.M. 1997. Herbaceous perennial plants: A treatise on their identification, culture, and garden attributes. 2nd Ed. Stipes Publishing, Champaign, IL.

Arnold, N.P., N.N. Barthakur, and M. Tanguay. 1998. Mutagenic effects of acute gamma irradiation on miniature roses: Target theory approach. HortScience 33:127-129.

Arunyanart, S. and S. Soontronyatara. 2002. Mutation induced by $\gamma$ and $x$-ray irradiation in tissue culture lotus. Plant Cell Tissue Organ Cult. 70:119-122.

Bermejo, A., J. Pardo, and A. Cano. 2011. Influence of gamma irradiation on seedless citrus production: Pollen germination and fruit quality. Food and Nutr. Sci. 2:169-180.

Broertjes, C., A.M. van Harten, and C. Broertjes 1988. Applied mutation breeding for vegetatively propagated crops. Elsevier, New York, NY.

Charbaji, L. and I. Nabulsi. 1999. Effect of low doses of gamma irradiation on in vitro growth of grapevine. Plant Cell Tissue Organ Cult. $57: 129-132$.

Dai, W. and V. Magnusson. 2012. Morphological variations in Buddleia induced by gamma ray irradiation. Hortacience 47:81-83.

Dao, T.B., P.D. Nguyen, Q.M. Do, T.H. Vu, T.L. Le, T.K.L. Nguyen, H.D. Nguyen, and X.L. Nguyen. 2006. In vitro mutagenesis of chrysanthemum for breeding. Plant Mutation Rpt. $1: 26-27$.

Datta, S.K., D. Chakrabarty, and A.K.A. Mandal. 2001. Gamma ray-induced genetic manipulations in flower colour and shape in Dendranthemum grandiflorum and their management through tissue culture. Plant Breed. 120:91-92.

Dilta, B.S., Y.D. Sharma, Y.C. Gupta, R. Bhalla, and B.P. Sharma. 2003. Effect of gamma-rays on vegetative and flowering parameters of chrysanthemum. J. Ornamental Hort. 6:328-334.

Driver, J.A. and A.H. Kuniyuki. 1984. In vitro propagation of paradox walnut rootstock. HortScience 19:507-509.

Fulcher, A., W.C. Dunwell, and D. Wolfe. 2003. Rudbeckia taxa evaluation. Southern Nurserymen's Assoc. Res. Conf 48:510-512.

Gottschalk, W. and G. Wolff. 1983. Induced mutations in plant breeding. Springer-Verlag, New York, NY.

Gupta, M.N. and R. Shukla. 1971. Mutation breeding of garden roses: Effects of gamma irradiation on some scented roses. Jap. J. Breeding 21:129-136.

Hong, C.X. 2006. Downy mildew of Rudbeckia fulgida cv. Goldsturm by Plasmopara halstedii in Virginia. Plant Dis. 90:1461.

Huitema, J.B.M., W. Preil, and J. De Jong. 1991. Methods of selection of low-temperature tolerant mutants of Chrysanthemum morifolium Ramat. using irradiated cell suspension cultures. III. Comparison of mutants selected with or without preselection in vitro at lowtemperature. Plant Breed. 107:135-140.

Li, R., H. Bruneau, and R. Qu. 2010. Morphological mutants of St. Augustinegrass induced by gamma ray irradiation. Plant Breed. 129:412-416.

Kristiansen, K. and K.K. Petersen. 2009. In vitro mutagenesis of Aster novi-belgii cultivars. Acta Hort. 836:207-214.

Kuksova, V.B., N.M. Piven, and Y.Y. Gleba. 1997. Somaclonal variation and in vitro induced mutagenesis in grapevine. Plant Cell Tissue Organ Cult. 49:17-27.

Murashige, T. and F. Skoog. 1962. A revised medium for rapid growth and bioassays with tobacco tissue cultures. Physiol. Plant. 15:473-497.

Palmer, I.E., R.E. Bir, N.P. Lynch, and T.G. Ranney. 2009. Crossability, cytogenetics, and reproductive pathways in Rudbeckia subgenus Rudbeckia. HortScience 44:44-48.

Palmer, I.E., D.H. Touchell, and T.G. Ranney. 2008. In-vitro polyploid induction of Rudbeckia spp. Southern Nurserymen's Assoc. Res. Conf. 53:186-189.

Perdue, R.E., Jr. 1957. Synapsis of Rudbeckia subg. Rudbeckia. Rhodora 59:293-299.

Rakotoarisoa, N.V., A. Andrianjaka, F.J. ZapataArias, R. Afza, and C. Mba. 2008. Inducing cold tolerance in Malagasy rice varieties IR 58614, Malady and Rojofotsy through in vitro mutagenesis. Plant Mutation Reports Vienna: Joint FAO/IAEA Division of Nuclear Techniques in Food and Agriculture, International Atomic Energy Agency 2:16-23.

Singh, V.N., B.K. Banerji, A.K. Dwivedi, and A.K. Verma. 2009. Effect of Gamma irradiation on African marigold (Tagetes erecta L.) cv. Pusa Narangi Gainda. J. Hort. Sci. 4:36-40.

Sparrow, A.H. 1954. Somatic mutations induced in plants by treatment with $X$ and $\gamma$ radiation. Caryologia. 6(suppl.): 1105 .

Stadler, L.J. 1944. The effect of X-rays upon dominant mutation in maize. Proc. Natl. Acad. Sci. USA 30:123-128.

Suprasanna, R., C. Rupali, N.S. Desai, and V.A. Bapat. 2008. Partial desiccation augments plant regeneration from irradiated embryogenic cultures of sugarcane. Plant Cell Tissue Organ Cult. 92:101-105.

van Harten, A.M. 1998. Mutation breeding, theory and practical applications. Cambridge Univ. Press, Cambridge.

Witjaksono and R.E. Litz. 2004. Effect of gamma irradiation on embryogenic avocado cultures and somatic embryo development. Plant Cell Tissue Organ Cult. 77:139-147. 